\title{
Fibromuscular dysplasia and coronary artery fistula: links to pulmonary hypertension
}

\author{
Wen Qian Zheng (1) ,' Suchet Kumar, ${ }^{2}$ Mohammad El-Hajjar ${ }^{2}$
}

${ }^{1}$ Internal Medicine, Albany Medical College, Albany, New York, USA

${ }^{2}$ Cardiology, Albany Medical College, Albany, New York, USA

\section{Correspondence to}

DrWen Qian Zheng;

zhengw@amc.edu

Accepted 13 March 2020

\section{DESCRIPTION}

A 68-year-old woman with a 22-year history of idiopathic pulmonary hypertension presents for coronary angiography after a nuclear stress test revealed an apical defect. Evaluation was prompted by worsening dyspnea on exertion.

During angiography, fibromuscular dysplasia (FMD) was noted in the long segment of the right brachial artery (figure 1), resulting in difficulty navigating the catheter. She also had a left ventricular aneurysm in the mid-anterior wall and an arteriovenous fistula between the mid-left anterior descending artery and the pulmonary artery (figure 2). The right heart catheterisation revealed that she had severe pulmonary hypertension (PA pressure $60 / 32 \mathrm{~mm} \mathrm{Hg}$, mean pressure $43 \mathrm{~mm} \mathrm{Hg}$ ) without left to right shunt. The cardiac output and cardiac index were $3.17 \mathrm{~L} / \mathrm{min}$ and $1.7 \mathrm{~L} / \mathrm{min} / \mathrm{m}^{2}$, respectively. Coronary arteries were patent and the left ventricular ejection fraction was normal.

Serial imaging from the past decade revealed progressive aneurysmal dilatation of the pulmonary arteries. The main pulmonary artery measures $4.6 \mathrm{~cm}$ in transverse diameter; left and right branches are both $4.0 \mathrm{~cm}$. In addition, she had bilateral common iliac artery aneurysms, $2.1 \mathrm{~cm}$ on the left and $1.8 \mathrm{~cm}$ on the right.

Ultimately, no invasive interventions were taken and the patient was optimised on medical therapy consistent of ambrisentan, tadalafil and sildenafil with symptomatic improvement. On follow-up, she was found well and reported a good quality of life.

\section{FIBROMUSCULAR DYSPLASIA}

FMD is a non-atherosclerotic, non-inflammatory arteriopathy that typically affects middle-aged women. Although commonly reported in renal and cervicocephalic arteries, they can be found in virtually all arteries, though the upper extremities involvement is very rare. ${ }^{1}$ FMD can lead to stenosis, aneurysms, dissection, arteriovenous fistula formation and thrombotic events of both the affected vascular bed and distant vessels. ${ }^{1-4}$ While FMD increases the risk of systemic hypertension, its association with pulmonary hypertension is less clear. There have been reports of disseminated FMD leading to pulmonary hypertension via stenosis or thromboembolism in the pulmonary arteries. ${ }^{5}{ }^{6} \mathrm{It}$ is possible that our patient's pulmonary hypertension originated via a similar mechanism but was not captured on imaging. We also hypothesise that FMD was a predisposing factor for the development of diffuse vasculopathy in this patient, possibly contributing to the progressive dilation of the pulmonary artery aneurysm.

Finally, according to recent recommendations, ${ }^{3}$ patients with FMD should undergo imaging to identify other affected vasculature and to screen for occult aneurysms and dissections. Low-dose aspirin may be reasonable for preventing thrombotic complications. Our patient was already on anticoagulation for atrial fibrillation, so aspirin was not added.

\section{CORONARY ARTERY FISTULAS}

Coronary artery fistulas (CAF) are rare and abnormal connections between a major vessel and other cardiac chambers. They are usually diagnosed incidentally on angiography. ${ }^{7}$ While most are asymptomatic, CAFs can result in angina, congestive heart failure and arrhythmias. For our patient, the fistula appeared to have no haemodynamic consequence at the time of angiography, thus a conservative approach was taken. However, the

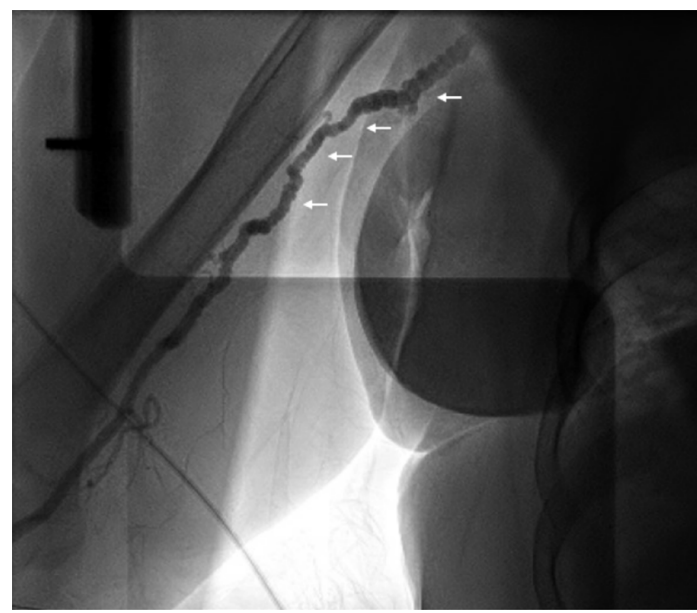

Figure 1 Fibromuscular dysplasia of the right brachial artery, with classic 'bead on a string' appearance.

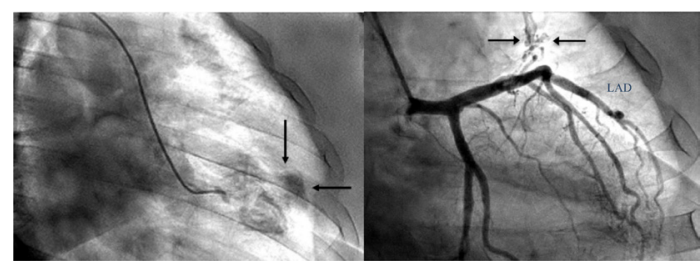

Figure 2 Left panel: left ventricular aneurysm, denoted by the arrows. Right panel: coronary angiography with black arrows denotes the fistula between the mid-left anterior descending artery (LAD) and the pulmonary artery, blue arrow denotes the LAD. 
abnormal connection between a coronary artery and the pulmonary artery has the potential to worsen her pulmonary hypertension. If the CAF becomes haemodynamically significant, blood would flow from the coronary vessel to the lower pressure circulation, increasing the pulmonary artery pressure. Therefore,

\section{Patient's perspective}

I have been diagnosed with idiopathic pulmonary hypertension for over 20 years and was originally only given $3-5$ years to live. Even though there are still no clear explanation for my disease, the findings here may bring us one step closer. I am grateful that the authors took the time to explain the imaging results in detail. These vascular findings may become important in my care in the future.

\section{Learning points}

- Patients with fibromuscular dysplasia (FMD) are at increased risk for vascular sequelae at distant vessels and should undergo screening for occult aneurysms, arteriovenous fistulas and dissections.

- Use of prophylactic aspirin should be considered for patients with FMD to prevent thrombotic complications.

- Coronary artery fistulas are often asymptomatic but can lead to cardiac sequlae. The onset of symptoms warrant evaluation for haemodynamic significance of the fistula and may merit repair. if the patient develops cardiac or respiratory symptoms in the future, she may warrant workup to evaluate for haemodynamic significance of the CAF. If necessary, many treatment options are available, ranging from transcatheter embolisation to surgical closure. $^{8}$

Contributors ME-H provided care for the patient. WQZ and SK planned and drafted the manuscript. ME-H critically reviewed the final manuscript.

Funding The authors have not declared a specific grant for this research from any funding agency in the public, commercial or not-for-profit sectors.

Competing interests None declared.

Patient consent for publication Obtained.

Provenance and peer review Not commissioned; externally peer reviewed.

\section{ORCID iD}

Wen Qian Zheng http://orcid.org/0000-0002-9255-0901

\section{REFERENCES}

1 Olin JW, Froehlich J, Gu X, et al. The United States Registry for fibromuscular dysplasia: results in the first 447 patients. Circulation 2012;125:3182-90.

2 Lüscher TF, Lie JT, Stanson AW, et al. Arterial fibromuscular dysplasia. Mayo Clin Proc 1987;62:931-52.

3 Gornik HL, Persu A, Adlam D, et al. First international consensus on the diagnosis and management of fibromuscular dysplasia. Vasc Med 2019;24:164-89.

4 Kadian-Dodov D, Gornik HL, Gu X, et al. Dissection and Aneurysm in Patients With Fibromuscular Dysplasia: Findings From the U.S. Registry for FMD. J Am Col/ Cardiol 2016;68:176-85.

5 Yano T, Kasahara Y, Tanabe N, et al. Juvenile pulmonary hypertension associated with fibromuscular dysplasia. Intern Med 2010;49:2487-92.

6 Fukuhara H, Kitayama H, Yokoyama T, et al. Thromboembolic pulmonary hypertension due to disseminated fibromuscular dysplasia. Pediatr Cardiol 1996;17:340-5.

7 Sunkara A, Chebrolu LH, Chang SM, et al. Coronary artery fistula. Methodist Debakey Cardiovasc J 2017;13:78-80.

8 Latson LA. Coronary artery fistulas: how to manage them. Catheter Cardiovasc Interv 2007;70:111-8

Copyright 2020 BMJ Publishing Group. All rights reserved. For permission to reuse any of this content visit

https://www.bmj.com/company/products-services/rights-and-licensing/permissions/

BMJ Case Report Fellows may re-use this article for personal use and teaching without any further permission.

Become a Fellow of BMJ Case Reports today and you can:

- Submit as many cases as you like

- Enjoy fast sympathetic peer review and rapid publication of accepted articles

- Access all the published articles

Re-use any of the published material for personal use and teaching without further permission

Customer Service

If you have any further queries about your subscription, please contact our customer services team on +44 (0) 2071111105 or via email at support@bmj.com.

Visit casereports.bmj.com for more articles like this and to become a Fellow 